units, the Madison model of care for the community, in the community, would be very difficult to surpass.

\section{References}

Stein, L. J. \& TEST, K. A. (1980) An alternative to mental hospital treatment. A conceptual model, treatment program, and clinical evaluation". Archives of General Psychiatry, 37, 392-397.

— \& - (1985). The Training in Community Living Model: A Decade of Experience. New Directions for Mental Health Services (No. 26), San Francisco: JosseyBass.

\title{
Compulsory admission to mental hospital in Thailand and England
}

\section{A visitor's view}

\author{
P. KuPITUKSA, Head of Research Unit, Psychology Department, Somdet Chaopraya \\ Hospital, Bangkok, Thailand and Honorary Research Fellow, Department of \\ Sociology, University of Lancaster; J. F. MACMILLAN, Senior Lecturer, University of \\ Birmingham and Honorary Consultant to Academic Unit, All Saints Hospital, Lodge \\ Road, Birmingham B18 5SO; and K. L. SoOTHILL, Senior Lecturer, Department of \\ Sociology, University of Lancaster, Lancaster
}

There are national differences relating to compulsory admission to mental hospitals. As a visitor from Thailand, it was of interest to me (PK) to compare procedures relating to admission, treatment and aftercare of the mentally ill in England and Thailand. In Thailand there is no equivalent of the Mental Health Act 1983. Although there are some legal provisions affecting patients' rights in Thai law, there are no legal provisions concerning 'detained' patients in mental hospitals.

Despite the fact that there is no legal provision for compulsory admission, there are patients who would be considered to have 'escaped' were they to leave hospital, and who may be compared with those admitted or detained under sections of the Mental Health Act 1983. However, without formal legal provision, the role and responsibilities of relatives are more extensive than in England. The relatives are required to take major responsibility for any mentally ill person. There are particular difficulties relating to the absence of catchment areas, as it is not uncommon for patients to be admitted to Somdet Chaopraya Hospital in Bangkok from distant rural areas, which places even more responsibility upon families.

\section{Admission procedures}

A 21 year-old single girl, in her last year at university in Bangkok, serves as a typical example of admission to Somdet Chaopraya Hospital. She lived with a brother and sister, who noted their relative to be sleeping and eating poorly and neglecting herself over a few weeks. She began to say she feared her sister had poisoned her food. The brother was also a student, and the sister in employment some distance from home. When the girl threatened her brother and sister with a knife they decided to seek help, and brought her to the hospital, tied up firmly with a strip of cloth.

Although many patients are admitted bound in this way in Nigeria, this is rare in Thailand. As there is no provision for a doctor, or indeed anyone else to call at home, the position in such a case is that the relatives must bring the patient to hospital. The doctor on duty that day retains medical responsibility for that patient thereafter, and the decision to admit rests with the doctor and the relatives. If both are in agreement then the patient will be admitted, regardless of the patient's view. The relatives are also required to take responsibility for payment for the 
bed, medication and laboratory investigations. As in England, relatives are required to give historical and other information to medical and paramedical personnel; and to be available for further interviews.

However, admission may not necessarily occur, as where a patient with more seniority and authority within the family than the accompanying relatives objects to the proposed admission. It is, for example, not usually possible for a mother or a wife to take the initiative to make psychiatric contact. In this situation another relative or neighbour with more authority would accompany the patient to hospital. In some cases the police may take the patient to hospital; but local police will not act outside their own province and then male neighbours may be called to assist where the patient is physically resisting.

The young girl described above was admitted to Somdet Chaopraya Hospital for reasons of her own health, for the safety of her sister and brother, and to relieve them of the burden of care. In Thailand, as in England, admission to hospital may occur where the patient or relatives are in danger, to remove the patient from stresses at home, and also to observe the patient to formulate a diagnosis, or for treatment.

The range or provision in England, where general practitioners may contact the psychiatric services, with some additional provision for social workers, psychiatric community nurses and inter hospital transfers, does not apply in Thailand, which relies upon family contact. In contrast, personal contact with psychiatric services occurs in a limited way in England within emergency clinics and some community based mental health services. Both countries share the contact made with psychiatrists in a general hospital unit dealing with self harming patients.

A set of case notes I examined in Birmingham described a situation which would have not occurred in Thailand. A 36 year-old widow was discharged home, with sole care of her two and a half year old child, following treatment for a depressive illness. Two days later a nurse visiting her home found the patient intoxicated with alcohol and benzodiazepines, contemplating suicide, and the possibility of taking the child with her. The patient was admitted under section 3 of the Mental Health Act 1983 that evening. In Thailand this woman would not have been left alone unless no relatives were available; then neighbours or friends would have taken the responsibility to take the patient to hospital.

\section{Treatment in hospital}

In England, patients who are detained for 72 hours, i.e. under Section 4, 136 or 135 , have the right to refuse treatment; patients who are admitted under Section 2 and 3 cannot refuse treatment. Doctors have the right to give treatment to patients under
Section 2 (28 days) but under Section 3 (six months) another doctor may be needed to review the treatment every three months. If doctors wish to give ECT, they must ask for a second opinion from the Commission.

In Thailand, the patient's relatives having signed the admission form, in practice the right of treatment is given to the patient's doctor. Doctors have full right to give any treatment they. consider suitable. However, it is customary for doctors to inform relatives about treatment, e.g. long-term medicine, ECT. In the case of patients coming from other provinces where it is inconvenient for relatives to come to see the doctor and the patient, doctors will make their own decisions as to treatment. However, if the patient needs an operation, or an autopsy has to be performed, permission from relatives is necessary. If the relatives object, the doctors cannot go ahead, but if relatives agree, a permission form must be signed. This of course pertains in England.

\section{Discharge from hospital}

In Thailand, only the patient's doctor can authorise discharge from hospital, although in exceptional circumstances another doctor may authorise discharge. Discharge usually follows when the patient has shown sufficient improvement, but also where patient and relatives are unwilling for a longer stay. At this stage the doctor has only the power of persuasion at his disposal to encourage the patient to stay. In addition, patients in employment may be discharged before they are fully improved; the financial pressure in Thailand is extreme as there is no state benefit, and where an individual is released from work for a limited time period, this is a serious constraint.

This situation contrasts with the situation in England where the patient may be discharged to continue with informal treatment by the responsible medical officer but also by the hospital managers, or by the Mental Health Review Tribunal. However, the procedure leading to discharge from hospital is much the same as most patients will have some leave of absence, prior to a full return to home. Patients admitted from distant places may have some limited financial assistance to permit return, and will be taken to the train by a social worker. Otherwise the responsibility lies with the family to arrange for the patient's return home.

\section{Aftercare and out-patient treatment}

The follow-up plan is formulated before the patient is discharged in both countries. In England, patients generally come to an out-patient clinic by appointment, but some are referred to their own general practitioner, community psychiatric nurses, or 
follow-up by a social worker, charge nurse, or by a doctor as a key worker may be arranged. There are some services at home such as giving oral or depot medication, and at the same time supportive therapy can be given, if need be, at home.

In Thailand, the patients visit the doctors by appointment (Soothill et al, 1981). If they live in another province and near another psychiatric unit, they would be transferred to that unit. If there is no psychiatric unit nearby they must come to receive treatment themselves or the family may collect the medicine for them. If neither patient nor family can conveniently collect, the hospital staff will send the medicine by post. In this situation the patient is expected to come to see the doctor at least once in every six months, or at once if there are side effects.

If admission does not occur, medical practitioners in Bangkok prescribe medication and arrange follow-up as in England. In Somdet Chaopraya hospital there are five doctors seeing around 150-200 patients every day on this basis. The relatives are available to bring the patient to the hospital at any time, regardless of the arranged appointment, if there is cause for concern.

Out-patients can discontinue their attendance by the simple expedient of failing to attend, as in England. The arrangement of sending letters two or three times to encourage attendance is common to both countries, and would appear to meet with equally variable success.

\section{Comment}

It seems that legal detention is suitable for use in developed countries such as England. People have more right to protect themselves, more freedom and more independence than in Thailand. Without the Mental Health Act, doctors would have no right to detain patients in hospital, even when violence or danger was clearly evident. The Act does not give complete rights to the doctor, who must exercise due caution in giving treatment. On the other hand, the patient is given the right to appeal against the Section and to refuse treatment.

It would appear that staff in psychiatric team work are in a psychologically and physically dangerous situation. In fact violence does not often occur, but can be sudden and unforeseen. One patient who was detained in hospital appealed to the Tribunal, and having been released, had a relapse into psychosis and killed somebody.
If criticism can be made of the Tribunal system, it is that having seen the patient only in a cross-section, the committee could be misled into minimising the patient's disturbance, especially in articulate and intelligent patients. A more serious criticism is that the questioning of the patient's doctor, sometimes appearing to be hostile, might in the eyes of the patient diminish his status and dignity, leading perhaps to a loss of respect and of confidence in him. Nevertheless, it is clear that the Mental Health Act affords both patient and doctor considerable protection. It also encourages more caution and patientinterest than would be the case without such an Act.

In developing countries such as Thailand, there are more extended families and the interpersonal relationship within the family is still close, and seniority is respected. Therefore it is relatively easy to force a hospital visit by psychological or other means. The doctor has freedom to give any treatment to the patient and is in a more powerful position than a doctor in a country which uses a Mental Health Act. The doctor is not personally involved in taking the patient to the hospital but authorises the admission and discharge of the patients with the co-operation of the patient's relatives. All responsibility for transport, for admission and discharge and for the costs of treatment and medicine falls upon the patient himself or relatives.

Each system seems to be suitable for each country. Systems and rules to be viable have to follow previous practice and tradition and there is bound to be development and progress with time. At present in Thailand there are more and more nuclear families and the average family size becomes smaller as Thailand becomes more industrialised. Some time in the future it seems certain that Thailand will have its first Mental Health Act.

This report is based on experience working in mental hospitals and discussion while doing research for the report on 'Compulsory Admissions to Mental Hospitals'. It may not be completely representative of all situations in both countries, but we have endeavoured to give a fair portrayal of the position.

\section{Reference}

SOOTHILL, K. L. et al (1981) Social control of deviants in six countries. Medical Science of Law, 21, 31-40.

\footnotetext{
A full list of references is available on request from $\mathrm{Dr}$ Macmillan.
} 